Sciendo

\title{
The Impact of Transparency in the Fight Against Corruption
}

\author{
$\mathrm{PhD}$ (c). Ardita Shehaj (Lafe)
}

Doi: $10.2478 / \mathrm{mjss}-2019-0065$

\author{
PhD. Ledjon Shahini
}

\begin{abstract}
Transparency and corruption are topics with high interest not only for researchers but especially for politicians, citizens and decision takers. Transparency is seen as an important instrument in the fight against corruption. Transparency and corruption phenomena are considered to be the most difficult to assess due to the subjectivity that characterizes them. For this reason, in this study we will show some results based on citizens perception. The method used to collect information regarding citizens perception is questionnaire and than the data are analyzed through a logistic model. Interesting results came out this research such as people who have been in contact with public institutions during the last months have 5,477 times more opportunities to give bribes compared to those who have not been in contact. Transparency is considered a good tool to fight corruption because based on the model result people who know the meaning of the right to information have $86.3 \%$ less chance to give bribes than people who do not know the meaning of the right of information. Whereas people who know the Albanian law on the right to information have $48 \%$ less chance of bribing than people who do not know this law. Based on these results it is necessary to raise citizen awareness on the use of the right to information as instrument to fight corruption.
\end{abstract}

Keywords: Corruption, Transparency, logistic model

\section{Introduction}

Transparency is considered as one of the main tools for good governance and the fight against corruption. Transparency means access to economic, political or legal information that is produced and administered by institutions. When information about the institutions is accessible to the public then the decision-making or the activity of these institutions can be monitored. A similar definition is used by Florini (2000) in her paper, where transparency is "publishing information that is relevant to the assessment of institutions". But Oliver (2004) extends the concept of transparency and argues that 'the transparency of an institution is not only related to the information being disclosed but it has to do with the availability of institutions to respond to public information requirements'. Stiglitz (2000) has defined transparency and states that transparency is 'another name for information'. Vishwanath and Kaufmann (1999), Bellver (2005), Hollyer (2011) use almost the same definition of transparency as "timely access to economic and political information for all stakeholders." So from this definition it is noticed that transparency does not have time barrier or economic barrier. Hood (2006) gives a very interesting comparison and says that 'transparency has reached the quasi-religious understanding of the debate on good governance and institutions'. Also Ball (2009) states that 'transparency is trying to involve accountability in public debate about good governance, because transparency is one of the fundamental elements of democratic societies'. Over the last few years, there have been many studies about the causes of corruption, which has a negative impact on the economic development of a country, but there is not much empirical research about the link between transparency and corruption. It was previously mentioned the definition of transparency, while the standard and widespread definition of corruption is abuse of the public position for personal gain. Only from the analysis of the above definitions seems to have an indirect link between these two concepts because if citizens would have full access to public information, then officials who exercise public functions would have fewer opportunities to perform 
personal gains, thus this will have an impact in reducing corruption.

A similar conclusion has been reached by Brunetti and Walesi (2003), who in their study conclude that if Nigeria, one of the most corrupt countries in the world, could increase their press freedom at the level of Norway, they would reduce their corruption levels in Western Europe. Suphacalasai (2005), in his empirical study, cited that corruption decreases considerably if the level of transparency is increased. While Besley and Pratt (2006) argue that transparency is needed to reduce corruption but is not a sufficient condition. They say that in addition to access to information, the ability to process information as well as the ability to act with the information received is a must. In their study 'Is transparency the key to fight corruption in rich countries?' Korlstad and Wig (2009) concluded that access to information has an effect on corruption. Transparency can reduce bureaucratic corruption by exposing corrupt activities at higher risk levels, by simplifying the procedures for selecting honest and more efficient people to serve as public servants and by facilitating employee promotion. Also, Korlstad and Wijig have argued that transparency can reduce political corruption by increasing politicians' accountability to the public. But they argue that transparency has an effect on corruption only in certain circumstances. Persons who have access to information should also have the opportunity to process the information and to act with the information received. Bahur and Grimes (2014) argue that transparency is the key to all forms of accountability, both horizontal (government), vertical (government) and diagonal (civil society) accountability. Peisakhin and Pinto (2010), in their study of the case of India concluded that transparency is an effective anti-corruption strategy while Lopez (2017) says government corruption is one of the most important issues faced by all countries. According to him, international organizations such as the IMF, the OSCE and the World Bank cannot guide governments to be less corrupt. In his study, he analyzes the Perception of Corruption Index (CPI) and the Open Budget Index $(\mathrm{OBI})$ and shows that there is a very high percentage of countries that have good results in terms of transparency and why countries are corrupt and proves that the most corrupt governments may have better transparency results not by publishing lies but by providing unspecified answers.

\section{Transparency in Albania}

In Albania, the right to information is a constitutional right sanctioned in the Constitution of the Republic of Albania, Article 23, which states that:

The right to information is guaranteed. Everyone has the right, in accordance with the law, to obtain information on the activities of state institutions as well as persons exercising public functions. Everyone is given the opportunity to attend meetings of elected collective bodies.

But this right is not only guaranteed by the constitution but also by the law no.119 / 2014 "On the Right to Information". The purpose of this law is to provide in practice maximum disclosure of public information. Also, public authorities that are or will be in continuous correspondence with citizens should demonstrate in front of them more accountability, will to provide information as indicators of their performance, but also should create more confidence in citizens and evaluate democratic principles. Based on the provisions of the Constitution, the right to information is regulated in two aspects: the right to be informed about the activity of state institutions as well as the right to be informed about the data's of employees that exercise state functions. Freedom of information Law provides two categories of information that should be made available to citizens in order to guarantee transparency:

1. Information that should be public with a request

2. Information that should be public without a request or the proactive transparency

Proactive transparency brings a variety of benefits not only to citizens but also to the institutions. According to Darbishire (2009), proactive transparency has an impact on reducing institutional expenditures and on promoting the integrity of civil servants. Encourages better information management, improves the internal flow of information to a public authority and thus contributes to improve efficiency within the institution. Darbishire also states that an important advantage of proactive disclosure of information, especially when it is done automatically and in real time, is that public employees find it difficult to deny the existence or manipulation of information. According to her, 
proactive transparency plays a key role in the accountability of institutions, but also in civic participation, thus having an impact on the fight against corruption. Although the law that guarantees transparency in Albania is a very good law on paper and even ranked sixth in the world, in practice the right to information and access to public information is not at the right levels. There are many issues regarding the proper level of implementation of this law. In the annual report 2017, the Commissioner for the Right to Information and Data Protection states that there are many problems regarding transparency in central institutions. The information published on the websites is not updated and the language used is not easily understandable to the citizens. The formats used to publish information are not easy accessible, readable and editable. All these factors makes transparency not realistic and still in its initial stages. Also the coordinators of freedom of information do not have the right knowledge or the right power to carry out this task. Similar problems are noticed even for local government institutions, where information is not published at all because most of the municipalities do not own a website or even in those cases where information is published is not easily accessible. Transparency is the key element of good governance especially in local government where the contact with the citizen is bigger. According to the Commissioner's report, transparency is at higher levels only for the independent institutions. This low level of transparency is reflected not only in quality but also in quantity. The graph below, clearly shows that the number of institutions that have met, even formally, the obligations to make transparency is too small.

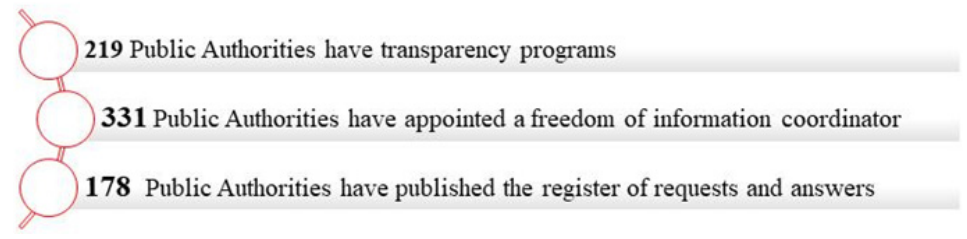

Source: Annual report 2018 of Information and Data Protection Commissioner

International monitoring partners assess that transparency is at low levels. The report of SIGMA/OECD for 2017 states that the approach to publish information on transparency programs (or otherwise proactive transparency) is not effective in the case of Albania. Transparency program is an official document that displays the categories of information that should be proactively published, but the way institutions publish information does not provide quick access to information. According to this report, a bureaucratic approach to institutional transparency does not contribute to the promotion of open government standards. The situation is seen as problematic even based on the perceptions of civil society, which is the main user of public information. According to a survey carried out by WEBER ${ }^{1}$, only $18 \%$ of civil society organizations perceive transparency and access to information properly applied in practice. Respondents also evaluate with 2 (in a rating of 1 to 5 ) the level of transparency, which means the publication of information is evaluated below the average level. In WEBER's report, "Despite the efforts to proactively publish public information, the transparency of government institutions remains a challenge both in terms of the lack of information and the bureaucratic approach that is being followed to manage institutional transparency." Also in the progress reports of the European Commission for Albania, transparency is one of the issues that still need improvement.

\section{Evaluating the Role of Transparency in Corruption through Logistic Models}

\subsection{Logistic models}

Transparency and corruption phenomena are considered to be the most difficult to assess due to the subjectivity that characterizes them. As such, a number of models have been used for their evaluation. One of these models that is being used to assess qualitative analyses and especially the data's gather by perception surveys is the logistic model. Logistic models are mostly used for

\footnotetext{
${ }^{1}$ https://weber-cep.s3.amazonaws.com/data/attachment_888/alb_weber_report-english-for_web.pdf
} 
probability analysis, or when the phenomenon we want to explain is in expressed by nominal data. This model explains the relationship between the binary dependent variable and one or more independent variables that may be nominal, common, interval or in the form of a report.

Since the dependent variable only takes values 0 and 1 , the linear regression form is unsuitable, while the logistic regression has a functional form such as: $f(z) \frac{1}{1+e-z}$, where $z$ goes to $\pm \infty$, hence $f(z)$ takes values 0 and 1 . Expressed in the form of a logistic equation the value of $\mathbf{z}$ is: $z=\beta_{0}+\beta_{1} x_{1}+\beta_{2} x_{2}+\ldots .+\beta_{n} x_{n}$ and the corresponding probability is:

$p_{(x)}=\frac{e^{\beta_{0}+\beta_{1} x_{1}+\beta_{2} x_{2}+\cdots+\beta_{n} x_{n}}}{e^{\beta_{0}+\beta_{1} x_{1}+\beta_{2} x_{2}+\cdots+\beta_{n} x_{n}+1}}=\frac{1}{1+e^{-\left(\beta_{0}+\beta_{1} x_{1}+\beta_{2} x_{2}+\cdots+\beta_{n} x_{n}\right)}}$

where $p(x)$ refers to the probability of $Y$.

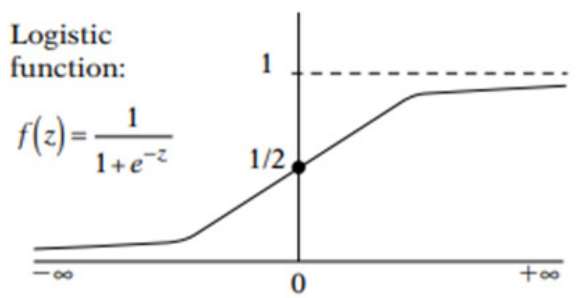

\subsection{Methodology}

To assess the role of transparency in the fight against corruption, the analysis was based on a study with questionnaires consisting of 27 questions. In this survey participated 697 people nationwide for a 7 days period, considering coverage by gender, age and region. The questionnaire was developed through online methods, and with binding responses in order to guarantee a $100 \%$ response rate. The purpose of the model is to determine various factors that affect the level of corruption in the country. To enable this analysis as dependent variables is taken whether the individuals asked have given additional payments or gifts (a variable that only receives the values yes and no where not $=0$ and yes $=1$ ). More specifically, the list of selected variables is reflected below:

- $Y=$ In addition to official fees, did you give an extra charge or a gift?

As explanatory variables are selected those that have a logical connection to the impact of corruption. So the independent variables used in this study are:

- $\quad X_{1}=$ Have you been in contact with public institutions during the last 12 months?

- $\mathrm{X}_{2}=$ In general, if you want to receive a service from the public administration, to what extent do you think it is acceptable to give bribes?

- $\quad \mathrm{X} 3=$ How widespread do you think is the problem of corruption in Albania?

- $\mathrm{X} 4$ = During the last three years, would you say the level of corruption in Albania is increased?

- $\quad \mathrm{X} 5$ = If you would report a corruption case, do you know where to report it?

- X6 = During the last 12 months, have you experienced or witnessed any corruption case?

- $\mathrm{X} 7=$ Is there corruption in the national public institutions in Albania?

- $\mathrm{X} 8=$ Do you know what right to information means?

- $\mathrm{X} 9=$ Do you know the Albanian law on the right to information?

The response rate for the 697 respondents was $100 \%$ because it was compulsory the fulfillment of the questionnaire.

Table No 1: Case Processing Summary

\begin{tabular}{|l|l|c|c|}
\hline Unweighted Cases $^{\text {a }}$ & $\mathrm{N}$ & Percent \\
\hline \multirow{3}{*}{ Selected Cases } & Included in Analysis & 697 & 100.0 \\
\cline { 2 - 4 } & Missing Cases & 0 & .0 \\
\cline { 2 - 4 } & Total & 697 & 100.0 \\
\hline Unselected Cases & 0 & .0 \\
\hline Total & 697 & 100.0 \\
\hline
\end{tabular}

Source: Author work (Results of the model) 
The statistical significance of the model it is worth mentioning that the model is statistically significant as we can see from the values of Sig. shown in table 2 on the Omnibus test results.

Table No 2: Omnibus Tests of the coeficients of the model

\begin{tabular}{|cl|c|c|c|}
\hline & & Chi-square & Df & Sig. \\
\hline \multirow{3}{*}{ Step 1 } & Step & 337.290 & 10 & .000 \\
& Block & 337.290 & 10 & .000 \\
& Model & 337.290 & 10 & .000 \\
\hline
\end{tabular}

Source: Author work (Results of the model)

The explanation of the model is of particular importance especially to draw conclusions both at the policy level and in the research one. For logistic models to indicate the level of disclosure, Cox \& Snell R Square and Nagelkerke R Square are used, where the latter is the same as the determinant coefficient used in linear models. Nagelkerke R Square is mostly used for logistic models to show the model's explanation. In the case of our model, we note that it takes values of 0.516 or $51.6 \%$. So our model has a level of explanation of over $50 \%$ and considering that we are dealing with a phenomena like corruption it should be noted that it is a more than satisfactory level. Table 3 gives a more complete presentation of the model results, where the above-mentioned coefficients also have the value of "-2 Log likelihood" which is similar to the $x 2$ (Chi-square) distribution of the table above. It is noted that for logistic models is used $\mathrm{R}^{2}$ according to Cox \& Snell, but since the values it takes are smaller than 1 , it is difficult to interpret and for that purpose $\mathrm{R}^{2}$ uses the Nagelkerke test.

Table No 3: Model Summary

\begin{tabular}{|c|c|c|c|}
\hline Step & -2 Log likelihood & Cox \& Snell R Square & Nagelkerke R Square \\
\hline 1 & $609.896^{\mathrm{a}}$ & .384 & .516 \\
\hline
\end{tabular}

Source: Author work (Results of the model)

All the selected variables to enable the explanation of our model are statistically significant except for $\mathrm{X} 3$ = How widespread do you think is the problem of corruption in Albania? which has a significance greater than 0.05. Unlike linear models, interpretation of logistic models has some features. Before we pass on the interpretation of the results, the form of the equation of our model that would be derived as follows:

$$
p_{(x)}=\frac{1}{1+e^{-\left(-2.249+1.7 \mathrm{X}_{1}+0.473 \mathrm{X}_{2}+0.34 \mathrm{X}_{3}+0.177 \mathrm{X}_{4}-0.156 \mathrm{X}_{5}+0.389 \mathrm{X}_{6}+0.738 \mathrm{X}_{7}+0.267 \mathrm{X}_{8}-1.985 \mathrm{X}_{9}-0.655 \mathrm{X}_{10}\right)}}
$$

As above mentioned, the interpretation of variables in logistic models is somewhat different than in multivariate models. To determine the probability that $p(x)=1$ is sufficient to give value to all depending variables of the equation. However, in order to have a simpler evaluation of the effect on these models, the $\beta \mathrm{i}$ values serve to understand the sign of the relation between independent and dependent variables. To interpret the variables effects in the model we analyze the values of $\operatorname{Exp} \beta i$. If $\operatorname{Exp} \beta i>1$, then with increasing of $x i$ increases and the possibility that the person has given bribes; if $\operatorname{Exp} \beta i=1$ bribing is not influenced by the increase of $x i$ and if $\operatorname{Exp} \beta i<1$ then by increasing the xi chances of giving bribes reduces. From the above equation we note that there is a positive link between the dependent variables and most of the independent variables, while for the variables that measure the knowledge of transparency, there is a negative link to the recognition of the law on the right of information. This connection can be attributed to the fact that transparency is the main element in the fight against corruption and the more is transparent the administration, the more narrow the opportunities for corruptive activities are. 
Table No 4: Variables in the Equation

\begin{tabular}{|c|c|c|c|c|c|c|c|c|c|}
\hline & \multirow{2}{*}{ B } & \multirow{2}{*}{ S.E. } & \multirow{2}{*}{ Wald } & \multirow{2}{*}{$\mathrm{Df}$} & \multirow{2}{*}{ Sig. } & \multirow{2}{*}{$\operatorname{Exp}(B)$} & \multicolumn{2}{|c|}{ 95\% C.I.for EXP(B) } \\
\hline & & & & & & & & Lower & Upper \\
\hline \multirow{10}{*}{ Step $1^{a}$} & $\mathrm{X} 1$ & 1.700 & .429 & 15.692 & 1 & .000 & 5.477 & 2.361 & 12.703 \\
\hline & $\mathrm{X} 2$ & .473 & .145 & 10.618 & 1 & .001 & 1.605 & 1.208 & 2.134 \\
\hline & $\mathrm{X} 3$ & .340 & .220 & 2.402 & 1 & 121 & 1.405 & .914 & 2.162 \\
\hline & $\mathrm{X} 4$ & 177 & .092 & 3.709 & 1 & .054 & 1.194 & .997 & 1.430 \\
\hline & X5 & .389 & .123 & 10.062 & 1 & .002 & 1.475 & 1.160 & 1.876 \\
\hline & $\mathrm{X} 6$ & .738 & .090 & 66.469 & 1 & .000 & 2.091 & 1.751 & 2.497 \\
\hline & $\mathrm{X} 7$ & 267 & 116 & 5.264 & 1 & .022 & 1.306 & 1.040 & 1.640 \\
\hline & $\mathrm{X} 8$ & -1.985 & .285 & 48.528 & 1 & .000 & 137 & .079 & .240 \\
\hline & X9 & -.655 & .225 & 8.496 & 1 & .004 & .520 & .334 & .807 \\
\hline & Constant & -2.249 & .832 & 7.298 & 1 & .007 & .106 & & \\
\hline
\end{tabular}

Source: Author work (Results of the model)

Analyzing the variables of the model we can find some interesting results which also consist in socioeconomic expectations. One of these important results is that people who have been in contact with public institutions during the last 12 months (X1) have 5,477 times more opportunities to give bribes compared to those who have not been in contact. Such a result is expected because Albania offers a limited number of online services which brings frequently individuals in contact with institutions. This is also evidenced by the fact that 870 out of the 967 people interviewed have had contact with institutions over the past 12 months. Given the fact that in many services there is a lack of legal clarity on well-defined procedures or timeframes, persons facing administrative structures are obliged to pursue bribery in order to receive the requested service. Under these conditions, the positive correlation between having contact and bribing is more than expected in the case of our country. What is interesting is the very high probability to give bribes in cases where the individual has had contacts with institutions. People who wanted to receive a service from public administration (X2) had 1,605 more opportunities to give bribe than people who did not want a service from the administration. This may also be due to the fact that citizens perceive a high level of corruption in public administration and because that $50 \%$ of respondents think that corruption is widespread in public institutions.

Also, the increase by one unit of the perception of spread level of corruption in Albania increases the opportunities to give bribes by 1.405 times. People who think that corruption over the last three years has grown have 1,194 times more opportunities to bribe than people who do not think so. Concerning the two above-mentioned results, it can be concluded that the high perception of the corruption phenomenon causes individuals to give more bribes as they think that they can easily get the services they want. The institutional structure dealing with prevention, awareness and detention of corruption is not unified and there are several institutions dealing with corruption starting from the Ministry of Justice, General Prosecutor's Office, High State Audit etc. The existence of many online platforms for reporting corruption and the presence of many institutions make citizens not have the right information on the institution responsible for reporting a corruptive case. This is proven by the fact that $47 \%$ of respondents do not know where to report a corruption case. An interesting result is that people who do not know where to report a corruption case have 1,475 times more opportunities to give bribes than people they know where to report. When analyzing the connection between corruption and being a witness in a corrupt activity interesting facts came out. People who have experienced or witnessed a corruption case in the last 12 months have 2,091 more opportunities to give bribes compared to people who have not witnessed this phenomenon over the past 12 months. This result is expected because these people who have experienced a corruption case also noticed that there was no punitive measure neither for the one was corrupted nor for the one who gave bribes. On the contrary bribery facilitated the process of obtaining the service. People who think corruption in national public institutions in Albania have 1,306 (or 30.6\%) more opportunities to give bribes than people who think that there is no corruption in Albanian institutions. 
Interesting results are noticed and when the relationship between corruption and transparency is analyzed. In fact, transparency is considered as one of the main instruments in the fight against corruption, but civic perception is not the same because from $88 \%$ of respondents that think they know the right to information, only $21 \%$ think that this law serves to fight corruption. Theoretically, it is expected that people who know the law on the right to information have a higher negative response towards bribing compared to people who know the right to information. This result is supported by the fact that persons who know the meaning of the right to information have $86.3 \%(1-0.137)$ less chance to give bribes than people who do not know the meaning of the right of information. Whereas people who know the Albanian law on the right to information have $48 \%$ less chance of bribing than people who do not know this law. This result can be due to the high difference between people who know the meaning of right to information and those who know the law. The law is known by $56 \%$ of respondents, while only $41 \%$ of respondents have had contact with this law.

\section{Conclusions}

Transparency is a very important element for good governance and fighting corruption. In the case of Albania, the legal and regulatory framework is very sophisticated on paper while in practice the level of transparency still remains a problem. Improving transparency of the institutions is a necessity and such a fact is noticed not only by the authority that monitors transparency but also by citizens, NGO and international organizations. A very low percentage of citizens know the right to information and even less have been in contact with the law on the right to information while most of them have given bribes. The fact that people who know the term the right to information have $86.3 \%$ less chance of bribing than people who do not know the term the right to information makes it necessary to raise citizen awareness on the use of the right to information as an instruments to fight corruption. Also, from the results of the model it is concluded that is necessary to reduce the physical contact with the institutions that provide public service in order to reduce the possibility to give bribes. The government should be oriented towards online delivery of the services, or one stop shops, as contact with the institutions significantly increases bribery.

\section{Reference}

Ball C (2009) What is transparency? Public Integrity

Bauhr, M. and Grimes, M. (2014) 'Indignation or Resignation: The Implications of Transparency for Societal Accountability'

Besley, T., \& Prat, A. (2006). Handcuffs for the grabbing hand? Media capture and government accountability. American Economic Review

Bellver, A., \& Kaufmann, D. (2005). Transparenting Transparency—Initial Empirics and Policy Applications. Preliminary draft discussion paper presented at the IMF conference on transparency and integrity June 6- 7 2005, Washington, DC: World Bank

Brunetti, A. \& Weder, B. (2003), 'A free press is bad news for corruption', Journal of Public Economics

Dorbishire H. (2009), Proactive Transparency: The future of the right to information? http://siteresources.worldbank.org/WBI /Resources/213798-1259011531325/6598384-1268250334206/Darbishire_Proactive_Transparency.pdf

Florini, A. (2000) "Does the Invisible Hand Need a Transparent Glove? The Politics of Transparency" https://ink.library.smu.edu.sg/cgi/viewcontent.cgi?article=3349\&context=soss_research

Hood C (2006) Transparency in historical perspective. In: Hood C and Heald D (eds) Transparency: The Key to Better Governance? New York: Oxford University Press

Kolstad, I. \& Wiig, A. (2009), 'Is Transparency the Key to Reducing Corruption in Resource Rich Countries?', World Development.

Lopez. S (2017), "Does Transparency Promote Less Corruption? Evidence From Around The World" https://www.westga.edu/ bquest/2017/transparency2017.pdf

OECD. (2002). Best Practices for Budget Transparency. Paris: OECD Publication Service

Oliver RW (2004) What is Transparency? New York: McGraw-Hill.

Peisakhin, Leonid, and Paul Pinto. 2010. Is Transparency an Effective Anti-Corruption Strategy? Evidence from A Field Experiment in India. Regulation \& Governance

Suphachalasai, S. (2005). Bureaucratic corruption and mass media. Environmental economy and policy research discussion paper series. Cambridge: University of Cambridge

Stiglitz, J. E. (2002a). On liberty, the right to know and public discourse: The role of transparency in public life. In M. Gibney (Ed.), Globalizing rights. Oxford: Oxford University Press.

Vishwanath, T. and D. Kaufmann (1999), Towards Transparency in Finance and Governance, World Bank.

Law No/ 119/2014 "On the right to information" http://www.idp.al/wp-content/uploads/2016/11/160-2014-DI.pdf

Annual Report of the Freedom of Information and Data Protection Commissioner 2017 http://www.idp.al/wpcontent/uploads/2018/02/RAPORTI_VJETOR_2017.pdf

Annual Report of the Freedom of Information and Data Protection Commissioner 2018 http://www.idp.al/wpcontent/uploads/2019/02/Raporti_Vjetor_2018_KDIMDP.pdf 